\title{
Editorial: in memoriam János G. Ángyán (1956-2017)
}

\author{
P. Reinhardt ${ }^{1,2} \cdot$ S. Lebègue $e^{3,4} \cdot$ P. R. Surján ${ }^{5}$
}

Received: 6 September 2018 / Accepted: 26 September 2018 / Published online: 15 November 2018

(c) Springer-Verlag GmbH Germany, part of Springer Nature 2018

\begin{abstract}
Introduction to the honorary volume dedicated to the memory of János G. Ángyán, died too early, on January 22, 2017, at the age of 60 . We recall some stations of his life and essential elements of his research.
\end{abstract}

Keywords Obituary $\cdot$ Editorial

János Ángyán, born in 1956 in Pécs, Hungary, spent his life and career between his hometown Budapest, his permanent office in Nancy, and in close collaboration with colleagues in Paris. It is therefore natural that three editors from these three places cover this honorary volume.

Already, his first (co-)signed publications show his broad vision of theoretical chemistry: As of 1983, we find applied work on antibiotics [1], a mathematical study on perturbation theory for time-independent Schrödinger equations [2], contributions to spectroscopy for optical rotatory strength calculations [3], and the main conductor of his further research, electrostatic potentials in molecular assemblies [4]. Even before having accomplished his thesis, János made contacts to the Paris' research groups, leading to postdoctoral stays in Toronto (Canada) and Paris (France), publishing regularly with colleagues from Hungary [5] and France

Published as part of the special collection of articles in memoriam of János Ángyán.

P. Reinhardt

Peter.Reinhardt@sorbonne-universite.fr

1 Laboratoire de Chimie Théorique, Faculté des Sciences, Sorbonne Université, Case Courrier 137, 4 Place Jussieu, 75252 Paris, France

2 CNRS UMR 7616, Laboratoire de Chimie Théorique, Case Courrier 137, 4 Place Jussieu, 75252 Paris, France

3 Université de Lorraine, LPCT, UMR 7019, 54506 Vandoeuvre-lès-Nancy, France

4 CNRS, LPCT, UMR 7019, 54506 Vandoeuvre-lès-Nancy, France

5 Laboratory of Theoretical Chemistry, Institute of Chemistry, Faculty of Science, ELTE Eötvös Loránd University, Budapest 112, P.O.B. 32 H-1518, Hungary
[6] while being officially a research associate in Budapest, Hungary.

In 1990-1991, he spent 2 years as a Humboldt fellow in the universities of Stuttgart (organic chemistry) and Bonn (theoretical chemistry) in Germany, before entering in 1991 the Centre National de la Recherche Scientifique (CNRS) in the laboratory of theoretical chemistry in Nancy, where he became a research director in 2000 , followed by, in 2001-2002, a 1-year stay at the Institut für Materialphysik of the University of Vienna, Austria, as a guest professor. In 2004, he moved to the Laboratory of Crystallography, Magnetic Resonance and Modelisation (CRM2) in the University Nancy I (now part of the University of Lorraine) in France. Recently, in 2016, he was elected external member of the Hungarian Academy of Sciences.

During this time, he published around 130 scientific papers with a large number of co-authors in different fields, supervised around a dozen of doctoral theses, and participated in the management of science as member of editorial boards (in particular of the present journal from 2000 to 2008), evaluation commissions, and organizer of various scientific meetings. Together with Bernard Silvi, he managed for instance in 2001 to gather around 70 scientists in Colle-sur-Loup in the south of France to discuss possible strategies to interpret chemical bonds with mathematical tools and a chemical language [7], known today as "conceptual DFT," and various indicators like Bader's theory of atoms in molecules or electron localization functionals.

Along his scientific career, Janos has been interested by a wide panel of topics-among them are the static and inductive electrostatic interactions in condensed media which are the common theme of many of his published 
works. He was particularly interested in the construction of models involving distributed multipole moments and distributed multipole polarizabilities, which lead for example to the optimally partitioned electric properties (OPEP) code [8]. The fast evaluation of accurate molecular electrostatic potentials is a challenging problem for the modeling of chemical systems in condensed media, and many charge fitting methods have been developed for this purpose. In order to go beyond this technology, Janos, among others, has proposed models in which electric multipoles are distributed over fragments [9-11]. He had examined methodological aspects of this problem analyzing the accuracy of the different distributed multipole and point charge models [12-17]. Even more important is his contribution to the calculation of induction and dispersion energies from distributed polarizabilities initiated in 1994 within the QTAIM partition scheme [18], resulting in the TPEP (topologically partitioned electric properties) program [19]. He further thoroughly investigated the properties of distributed polarizability techniques [20-27]. In the same way, he has addressed the calculation of dispersion energy from distributed dynamic polarizabilities. For all of these distributed quantities, his priority was to devise efficient methods without searching for physicochemical interpretation of individual numbers.

A vast field of applications of these functional and series expansions is the treatment of dispersion interactions in a density functional framework. In this context, in the quest to improve systematically density functional theory, he collaborated closely with A. Savin on range-separated DFT, publishing fundamental studies on perturbation theory $[28,29]$ and the random-phase approximation (RPA) [30], leading to various implementations for the molecular case (in the program package Molpro). Following his stay in Vienna, he broadened his expertise to include solid state physics: For instance, he contributed to the implementation [31] of the RSHX functionals in the VASP code and to a study [32] of the cohesive properties of graphite using RPA. Also, he initiated the implementation [33] of Grimme's D2 correction in the same code, a work which was the beginning of a series of papers [33-36] on the implementation of different schemes to correct for the missing dispersion forces of local and semi-local density functionals in solids. Those features are now widely used by the VASP community. Related to these topics, one of the last meetings he organized was a CECAM workshop in Nancy in June 2016, entitled "Density- and response density-based models for Intermolecular Interactions in Molecular Assemblies and in Solids."

Besides his scientific activities, we remember a lively person, open to discuss and to animate, with a strong interdisciplinary, international, and cultural background, summarized in one of his ex libris designed by himself.

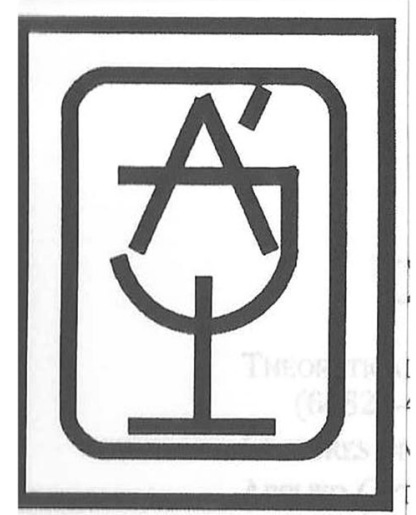

In the present volume, we could collect in 33 articles many of the different facets of János' work, ongoing collaborations with colleagues all over the world, having come too soon to an end, and ideas which may be further developed. He left us, but souvenirs and achievements will remain.

We thank all contributors and referees for their work, and Mrs. Ananthanarayanan of Springer for her patience in handling the manuscripts.

Paris-Nancy-Budapest, August 2018.

\section{References}

1. Ángyán JG, Surján PR, Náray-Szabó G (1983) Quantum chemical studies on serine proteinases. Stud Biophys 93:221-224

2. Surján PR, Ángyán JG (1983) Perturbation theory for nonlinear time-independent Schrödinger equations. Phys Rev A 28:45-48

3. Ángyán JG, Surján PR (1983) Bond orbital approach for optical rotatory strength calculations. Theor Chim Acta 63:43-54

4. Ángyán JG, Náray-Szabó G (1983) Comparison of protein electrostatic potential along the catalytic triad of serine proteinases. $\mathrm{J}$ Theor Biol 103:349-356

5. Perczel A, Ángyán JG, Kajtár M, Viviani W, Rivail J-L, Marcoccia J-F, Csizmadia IG (1991) Peptide models. I. The topology of selected peptide conformational potential energy surfaces (glycine and alanine derivatives). J Am Chem Soc 113:6256-6365

6. Ángyán JG, Colonna-Cesari F, Tapia O (1990) Analytical first and second energy derivatives in the polarization model. Chem Phys Lett 166:180-188

7. Ángyán JG, Silvi B (2001) Preface to the ChemBond issue. Theor Chem Acc 105:269

8. Ángyán JG, Chipot C, Dehez F, Hättig C, Jansen G, Millot C (2003) OPEP: a tool for the optimal partitioning of electric properties. J Comput Chem 24:997-1008

9. Nagy P, Ángyán JG, Náray-Szabó G, Peinel G (1987) Molecular electrostatic fields from bond fragments. Int J Quant Chem 31:927

10. Ángyán JG (2000) Chemical building blocks in quantum chemical calculations. Perspective on "The density matrix in many-electron quantum mechanics I. Generalized product functions. Factorization and physical interpretation of the density matrices". Theor Chem Acc 103:238 
11. Chipot C, Ángyán JG, Ferenczy GG, Scheraga HA (1993) Transferable net atomic charges from distributed multipole analysis for the description of electrostatic properties. A case study of saturated hydrocarbons. J Phys Chem 97:6628

12. Colonna F, Evleth E, Ángyán JG (1992) Critical analysis of electric field modeling: formamide. J Comput Chem 13:1234

13. Dillet V, Rinaldi D, Ángyán JG, Rivail JL (1993) Reaction field factors for a multipole distribution in a cavity surrounded by a continuum. Chem Phys Lett 202:18

14. Ángyán JG, Chipot C (1994) A comprehensive approach to molecular charge density models: from distributed multipoles to fitted atomic charges. Int J Quant Chem 52:17

15. Surján P, Ángyán JG (1994) The reliability of point charge models for the representation of environment effects in ab initio calculations. Chem Phys Lett 225:258

16. Hättig C, Jansen G, Hess BA, Ángyán JG (1997) Intermolecular interaction energies by topologically partitioned electric properties. II. Dispersion energies in one- centre and multicentre expansions. Mol Phys 91:145

17. Chipot C, Ángyán JG, Millot C (1998) Statistical analysis of distributed multipoles derived from molecular electrostatic potentials. Mol Phys 94:881

18. Ángyán JG, Jansen G, Loos M, Hättig C, Heß BA (1994) Distributed polarizabilities using the topological theory of atoms in molecules. Chem Phys Lett 219:267

19. Hättig C, Jansen G, Heß BA, Ángyán JG (1997) Intermolecular interaction energies by topologically partitioned electric properties. II. Dispersion energies in one-centre and multicentre expansions. Mol Phys 91:145-160

20. Hättig C, Heß BA, Jansen G, Ángyán JG (1996) Topologically partitioned dynamic polarizabilities using the theory of atoms in molecules. Can J Chem 74:976

21. Stone AJ, Hättig C, Jansen G, Ángyán JG (1996) Transferability of topologically partitioned polarizabilities: the case of n-alkanes. Mol Phys 89:595

22. Reis H, Papadopoulos MG, Hättig C, Ángyán JG, Munn RW (2000) Distributed first and second hyperpolarizabilities: an improved calculation of nonlinear optical susceptibilities of molecular crystals. J Chem Phys 112:6161

23. Celebi N, Ángyán JG, Dehez F, Millot C, Chipot C (2000) Distributed polarizabilities derived from induction energies. A finite perturbation approach. J Chem Phys 112:2709

24. Dehez F, Soetens JC, Chipot C, Ángyán JG, Millot C (2000) Determination of distributed polarizabilities from a statistical analysis of induction energies. J Phys Chem A 104:1293
25. Dehez F, Chipot C, Millot C, Ángyán JG (2001) Fast and accurate determination of induction energies: reduction of topologically distributed polarizability models. Chem Phys Lett 338:180

26. in het Panhuis M, Popelier PLA, Munn RW, Ángyán JG (2001) Distributed polarizability of the water dimer: field-induced charge transfer along the hydrogen bond. J Chem Phys 114:7951

27. Soteras I, Curutchet C, Bidon-Chanal A, Dehez F, Ángyán JG, Orozco M, Chipot C, Luque FJ (2007) Derivation of distributed models of atomic polarizability for molecular simulations. J Chem Theory Comput 3:1901

28. Ángyán JG, Gerber IC, Savin A, Toulouse J (2005) van der Waals forces in density-functional theory: perturbational long-range electron-interaction corrections. Phys Rev A 72:012510

29. Ángyán JG (2008) Rayleigh-Schrdinger many-body perturbation theory for density functionals: a unified treatment of one- and two-electron perturbations. Phys Rev A 78:022510

30. Toulouse J, Zhu W, Ángyán JG, Savin A (2010) Range-separated density-functional theory with random phase approximation: detailed formalism and illustrative applications. Phys Rev A 82:032502

31. Gerber IC, Ángyán JG, Marsman M, Kresse G (2007) Range separated hybrid density functional with long-range Hartree-Fock exchange applied to solids. J Chem Phys 127:054101

32. Lebègue $\mathrm{S}$, Harl J, Gould T, Ángyán JG, Kresse G, Dobson JF (2010) Cohesive properties and asymptotics of the dispersion interaction in graphite by the random phase approximation. Phys Rev Lett 105:196401

33. Bučko T, Hafner J, Lebègue S, Ángyán JG (2010) Improved description of the structure of molecular and layered crystals: abinitio DFT calculations with van der Waals corrections. J Phys Chem A 114:11814

34. Bučko T, Lebègue S, Ángyán JG, Hafner J (2013) TkatchenkoScheffler van der Waals correction method with and without selfconsistent screening applied to solids. Phys Rev B 87:064110

35. Bučko T, Lebègue S, Ángyán JG, Hafner J (2014) Extending the applicability of the Tkatchenko-Scheffler dispersion correction via iterative Hirshfeld partitioning. J Chem Phys 141:034114

36. Gould T, Lebègue S, Ángyán JG, Bučko T (2016) A fractionally ionic approach to polarizability and van der Waals many-body dispersion calculations. J Chem Theory Comput 12:5920 